Article

\title{
Design and Engineering of an Efficient Peroxidase Using Myoglobin for Dye Decolorization and Lignin Bioconversion
}

\author{
Wen-Jie Guo ${ }^{1}$, Jia-Kun $\mathrm{Xu}^{2}{ }^{2}$, Sheng-Tao Wu ${ }^{1}$, Shu-Qin Gao ${ }^{3}$, Ge-Bo Wen ${ }^{3}$, Xiangshi Tan ${ }^{4}$ and Ying-Wu Lin ${ }^{1,3, *}$ \\ 1 School of Chemistry and Chemical Engineering, University of South China, Hengyang 421001, China; \\ 20192005210167@usc.edu.cn (W.-J.G.);wushengtao@usc.edu.cn (S.-T.W.) \\ 2 Key Laboratory of Sustainable Development of Polar Fisheries, Ministry of Agriculture and Rural Affairs, \\ Yellow Sea Fisheries Research Institute, Chinese Academy of Fishery Sciences, Laboratory for Marine Drugs \\ and Byproducts of Pilot National Laboratory for Marine Science and Technology, Qingdao 266071, China; \\ xujk@ysfri.ac.cn \\ 3 Key Laboratory of Protein Structure and Function of Universities in Hunan Province, University of South \\ China, Hengyang 421001, China; 2014001853@usc.edu.cn (S.-Q.G.); wengebo@usc.edu.cn (G.-B.W.) \\ 4 Department of Chemistry \& Institute of Biomedical Science, Fudan University, Shanghai 200433, China; \\ xstan@fudan.edu.cn \\ * Correspondence: ywlin@usc.edu.cn; Tel.: +86-734-8282375
}

check for updates

Citation: Guo, W.-J.; Xu, J.-K.; Wu, S.-T.; Gao, S.-Q.; Wen, G.-B.; Tan, X.; Lin, Y.-W. Design and Engineering of an Efficient Peroxidase Using Myoglobin for Dye Decolorization and Lignin Bioconversion. Int. J. Mol. Sci. 2022, 23, 413. https://doi.org/ $10.3390 /$ ijms 23010413

Academic Editors: Angela Lombardi, Flavia Nastri and Linda Leone

Received: 27 November 2021

Accepted: 30 December 2021

Published: 30 December 2021

Publisher's Note: MDPI stays neutral with regard to jurisdictional claims in published maps and institutional affiliations.

Copyright: (C) 2021 by the authors. Licensee MDPI, Basel, Switzerland. This article is an open access article distributed under the terms and conditions of the Creative Commons Attribution (CC BY) license (https:// creativecommons.org/licenses/by/ $4.0 /)$.

\begin{abstract}
The treatment of environmental pollutants such as synthetic dyes and lignin has received much attention, especially for biotechnological treatments using both native and artificial metalloenzymes. In this study, we designed and engineered an efficient peroxidase using the $\mathrm{O}_{2}$ carrier myoglobin $(\mathrm{Mb})$ as a protein scaffold by four mutations (F43Y/T67R/P88W/F138W), which combines the key structural features of natural peroxidases such as the presence of a conserved His-Arg pair and Tyr/Trp residues close to the heme active center. Kinetic studies revealed that the quadruple mutant exhibits considerably enhanced peroxidase activity, with the catalytic efficiency $\left(k_{\mathrm{cat}} / K_{\mathrm{m}}\right)$ comparable to that of the most efficient natural enzyme, horseradish peroxidase (HRP). Moreover, the designed enzyme can effectively decolorize a variety of synthetic organic dyes and catalyze the bioconversion of lignin, such as Kraft lignin and a model compound, guaiacylglycerol- $\beta$-guaiacyl ether (GGE). As analyzed by HPLC and ESI-MS, we identified several bioconversion products of GGE, as produced via bond cleavage followed by dimerization or trimerization, which illustrates the mechanism for lignin bioconversion. This study indicates that the designed enzyme could be exploited for the decolorization of textile wastewater contaminated with various dyes, as well as for the bioconversion of lignin to produce more value-added products.
\end{abstract}

Keywords: heme enzymes; protein design; dye-decolorizing peroxidase; kraft lignin bioconversion

\section{Introduction}

In the last decade, the environmental pollution caused by organic chemicals has received much attention. The main sources of organic matter in wastewater are synthetic dyes from the textile industry [1] and lignin from the paper industry [2]. For example, various dyes such as anthraquinones, azo, and triphenylmethane compounds in wastewater threaten aquatic organisms and human health [3]. Meanwhile, lignocellulosic biomass has great potential as raw material to produce more value-added products such as glucose, fuel, and furfural through biologically refining [4]. Therefore, it is important to effectively degrade organic dyes and utilize lignin in wastewater for environmental treatment.

At present, chemical methods are most used to purify or degrade synthetic dyes and lignin in polluted water. The main degradation methods include physical processes such as membrane filtration, precipitation, flotation, adsorption, and ion exchange, and chemical processes such as electrolysis and chemical reduction/oxidation [5]. However, due to its complex structure, amorphous and non-uniform nature, the degradation of lignin generally 
occurs at a high temperature $\left(200-500^{\circ} \mathrm{C}\right)[6]$. On the other hand, the addition of catalysts may reduce the temperature required for the reaction. For example, the conversion of lignin may occur at $200{ }^{\circ} \mathrm{C}$ via a fragmentation-hydrogenolysis process with $\mathrm{Ni} / \mathrm{C}$ catalyst [7].

In addition to chemical and physical methods, biotechnological treatments use both native and artificial metalloenzymes such as heme enzymes and others [8-13]. Comparatively, the biologically catalytic process often occurs under mild reaction conditions. Both organic dyes and lignin in wastewater could be degraded by bacteria and fungi. The main functional enzymes include dye-decolorizing peroxidase (DyPs), lignin peroxidase, manganese peroxidase, and versatile peroxidases in these organisms [14-16]. Recently, the use of enzymes in organisms to catalyze degradation is the focus of the research. As found in eukaryotes and prokaryotes, the heme-containing peroxidases use $\mathrm{H}_{2} \mathrm{O}_{2}$ as an electron acceptor to catalyze the oxidation of a large number of substrates $[17,18]$. Moreover, other metalloenzymes such as laccase and $\beta$-esterase can also play a catalytic role in biodegradation [19].

Notably, recent studies have shown that DyPs show great potential for degrading lignin and a variety of synthetic dyes, making them potentially useful in wastewater bioremediation [20]. DyPs are classified into four subfamilies (A-D) according to their sequence characteristics. Generally, different types of DyPs have different catalytic properties toward lignin model compounds [21,22]. There are also reports suggesting the mechanism of how A-type DyPs oxidize bulky dye molecules such as reactive blue 19 (RB19) and lignin polymers [23]. These achievements highlight the potential of DyPs as biocatalysts while they work at relatively low $\mathrm{pH}$ values $(\mathrm{pH} 3-4)$ [24].

To design efficient heme peroxidases, we used the $\mathrm{O}_{2}$ carrier myoglobin $(\mathrm{Mb})$ as a model protein by modification of the heme center (Figure 1A). For example, by introducing a distal Tyr residue (F43Y mutation), we discovered a new post-translational modification in F43Y Mb that forms a novel Tyr-heme cross-link [25]. To mimic the heme active site of natural peroxidases containing a conserved His-Arg pair more closely, we constructed a double mutant F43Y / T67R Mb by further introducing a distal Arg67 in F43Y Mb (Figure 1B), which improves the protein stability and significantly enhances the peroxidase activity [26]. Recently, we applied the double mutant F43Y/T67R Mb for the bioconversion of lignin with satisfying results [27]. Moreover, natural DyPs contain multiple Tyr and Trp residues responsible for electron transfer in dye decolorization [28,29]. Inspired by this structural feature, in previous studies, we constructed two triple mutants F43Y/T67R/F138W Mb (termed YRW Mb) and F43Y/F138W/P88W Mb (termed YW2 Mb) by introducing single or double Trp residues close to the heme active site [30-32]. Specifically, the triple mutant YW2 $\mathrm{Mb}$ exhibited considerably enhanced DyP activity, with the catalytic efficiency $\left(k_{\mathrm{cat}} / K_{\mathrm{m}}\right)$ $\sim 7$-fold higher than that of $V c \mathrm{DyP}$, which is close to that of TfuDyP [33,34].

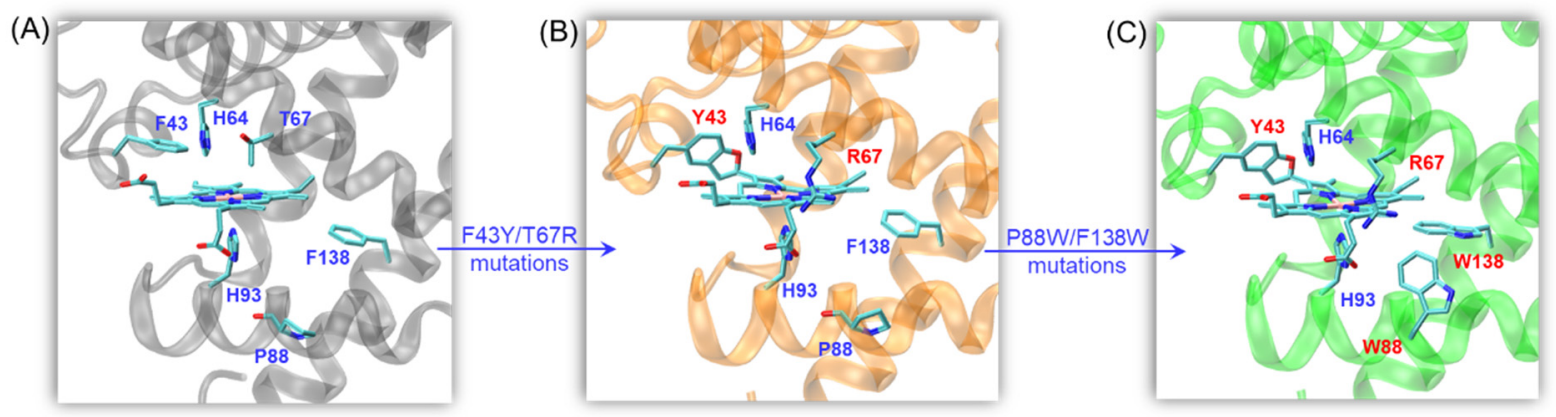

Figure 1. (A) X-ray crystal structure of wild-type (WT) Mb (PDB code 1JP6[35]) showing the heme active site; (B) X-ray crystal structure of F43Y/T67R Mb double mutant showing the double Tyrheme cross-links (PDB code 6JP1[26]); (C) The modeling structure of F43Y/T67R/P88W/F138W Mb quadruple mutant showing the location of Trp88 and Trp138.

With these achievements, we envisaged that the combination of not only the conserved His-Arg pair but also the electron-transfer Trp residues in $\mathrm{Mb}$ will confer a functional peroxidase. 
To test this hypothesis, we constructed a quadruple mutant F43Y/T67R/P88W/F138W Mb (termed YRW2 Mb, Figure 1C). As shown in this study, the quadruple mutant exhibits considerable peroxidase activity such as DyP activities toward a variety of synthetic dyes. Moreover, it is capable of lignin bioconversion, such as depolymerization of Kraft lignin and the dimer lignin model compound, guaiacylglycerol- $\beta$-guaiacyl ether (GGE).

\section{Results and Discussion}

\subsection{Peroxidase Activity}

The quadruple mutant YRW2 Mb was expressed and purified using the same procedure as that for $\mathrm{WT} \mathrm{Mb} \mathrm{[35],} \mathrm{which} \mathrm{was} \mathrm{further} \mathrm{confirmed} \mathrm{by} \mathrm{ESI-MS} \mathrm{analysis} \mathrm{(Figure} \mathrm{S1).}$ We first investigated the $\mathrm{H}_{2} \mathrm{O}_{2}$-dependent peroxidase activity of YRW2 $\mathrm{Mb}$ in the oxidation of ABTS (Figure S2). The results showed that the enzyme exhibited a turnover number $\left(k_{\text {cat }}\right)$ of $40.6 \pm 0.9 \mathrm{~s}^{-1}$ and a $K_{\mathrm{m}}$ of $5.5 \pm 0.4 \mathrm{mM}$ for $\mathrm{H}_{2} \mathrm{O}_{2}$. No obvious inhibition effect was observed for $\mathrm{H}_{2} \mathrm{O}_{2}$ at a concentration $>20 \mathrm{mM}$, suggesting the tolerance of $\mathrm{H}_{2} \mathrm{O}_{2}$, which is similar to that of $\mathrm{YW} 2 \mathrm{Mb}$, as reported in the previous study [31].

We then evaluated the peroxidase activity of the quadruple mutant YRW2 $\mathrm{Mb}$ and the triple mutant $\mathrm{YW} 2 \mathrm{Mb}$, using both guaiacol and ABTS as the typical substrates under the steady-state conditions at a concentration of $20 \mathrm{mM} \mathrm{H}_{2} \mathrm{O}_{2}$. The obtained parameters are listed in Table 1, which are compared with those of WT Mb and mutants, as well as HRP. As shown in Figure 2 and Table 1 for the oxidation of guaiacol and ABTS at $\mathrm{pH} 7.0,25^{\circ} \mathrm{C}$, although the quadruple mutant YRW2 $\mathrm{Mb}$ exhibited similar catalytic rates $\left(k_{\mathrm{cat}}\right)$ to those of YW2 $\mathrm{Mb}$ under the same conditions, it showed largely decreased $K_{\mathrm{m}}$ values compared with the triple mutant. As a consequence, the catalytic efficiency of YRW2 Mb in oxidizing these two substrates is $\sim 2.3$ fold higher than those of YW2 Mb. It should be noted that although the contribution of R67 in $k_{\text {cat }}$ could hardly be deduced between the quadruple and triple mutant, its role was indicated by the comparison of F43Y Mb and F43Y/T67R Mb (Table 1). Moreover, a distal Arg was demonstrated to be essential for regulating the structure and reactivity of artificial heme enzymes [36,37].

As further compared in Table 1 for guaiacol oxidation, YRW2 Mb showed an overall catalytic efficiency $\left(k_{\text {cat }} / K_{\mathrm{m}}=103,400 \mathrm{M}^{-1} \mathrm{~s}^{-1}\right) \sim 4$-fold, $\sim 11.5$-fold, $\sim 26$-fold, and $\sim 940$-fold higher than that of F43Y/T67R/F138W Mb (termed YRW Mb), F43Y/T67R Mb, F43Y Mb, and $\mathrm{WT} \mathrm{Mb}$, respectively, under the same conditions [32,38]. Moreover, the catalytic efficiency is much higher than that of natural lignin peroxidase $\left(k_{\mathrm{cat}} / K_{\mathrm{m}}=72,000 \mathrm{M}^{-1} \mathrm{~s}^{-1}\right)$ [39], as well as the most efficient HRP (Table 1) [40]. These results indicate that the combination of the quadruple mutations in $\mathrm{Mb}$ dramatically enhances the peroxidase activity, even exceeding that of the natural peroxidases.

For the oxidation of ABTS, the catalytic efficiency of the quadruple mutant is $~ 14$-fold, $\sim 37$-fold, and $\sim 287.5$-fold higher than that of F43Y/T67R Mb, F43Y Mb, and WT Mb, respectively $[32,38]$, which could be attributed to both the enhanced $k_{\text {cat }}$ value and decreased $K_{\mathrm{m}}$ value. When compared to the triple mutant $Y R W \mathrm{Mb}$, YRW2 Mb exhibits both higher $k_{\text {cat }}$ and $K_{\mathrm{m}}$ values, resulting in slightly lower catalytic efficiency. Moreover, although the quadruple mutant exhibits a slightly lower $k_{\text {cat }}$ value compared to that of the triple mutant YW2 Mb, it shows a lower $K_{\mathrm{m}}$ value, resulting in $\sim 2.3$-fold higher catalytic efficiency. These observations suggest that the presence of the distal Arg67 and Trp88 close to the heme group may fine-tune both the protein reactivity and the binding of substrate. It is worth noting that due to the significant decrease in $K_{\mathrm{m}}$ value compared to that of the natural enzyme, the catalytic efficiency of the quadruple mutant is similar to those of HRP, as previously determined under the optimized conditions ( $\mathrm{pH} 4.6-5.0)$ (Table 1) [40,41]. 
Table 1. Kinetic parameters for $\mathrm{H}_{2} \mathrm{O}_{2}$-dependent oxidation of guaiacol and ABTS catalyzed by $\mathrm{Mb}$ and its mutants. Measurements were performed in $50 \mathrm{mM}$ potassium phosphate buffer at $\mathrm{pH}$ 7.0, $25^{\circ} \mathrm{C}$. The parameters of natural lignin peroxidase and HRP are shown for comparison.

\begin{tabular}{cccc}
\hline Enzyme & $\boldsymbol{k}_{\text {cat }}\left(\mathbf{s}^{-\mathbf{1}}\right)$ & $\boldsymbol{K}_{\mathbf{m}}(\mathbf{m M} / \boldsymbol{\mu M})$ & $\boldsymbol{k}_{\text {cat }} / \boldsymbol{K}_{\mathbf{m}}\left(\mathbf{M}^{-\mathbf{1}} \mathbf{s}^{-\mathbf{1}}\right)$ \\
\hline Guaiacol $\left(K_{\mathrm{m}}, \mathrm{mM}\right)$ & & & \\
WT Mb [38] & $0.4 \pm 0.1$ & $3.53 \pm 0.05$ & 110 \\
F43Y Mb [38] & $10.7 \pm 0.4$ & $2.67 \pm 0.21$ & 4000 \\
F43Y/T67R Mb [32] & $23.5 \pm 0.3$ & $2.61 \pm 0.06$ & 9000 \\
F43Y/T67R/F138W Mb [32] & $27.7 \pm 0.8$ & $0.79 \pm 0.07$ & 35,000 \\
F43Y/F138W/P88W Mb & $11.3 \pm 0.2$ & $0.25 \pm 0.01$ & 44,380 \\
F43Y/T67R/P88W/F138W Mb & $11.0 \pm 0.2$ & $0.11 \pm 0.01$ & 103,400 \\
Lignin peroxidase [39] & $7.7 \pm 0.0$ & $0.16 \pm 0.00$ & 48,000 \\
HPR [40] & $420 \pm 40.0$ & $5.8 \pm 0.70$ & 72,000 \\
ABTS (Km, $/$ M) & & & \\
WT Mb [38] & $0.55 \pm 0.02$ & $124 \pm 15$ & 4440 \\
F43Y Mb [38] & $12.0 \pm 0.68$ & $351 \pm 40$ & 34,190 \\
F43Y/T67R Mb [32] & $50.8 \pm 3.6$ & $567 \pm 68$ & 89,600 \\
F43Y/T67R/F138W Mb [32] & $31.5 \pm 0.6$ & $16 \pm 2$ & $1,970,000$ \\
F43Y/F138W/P88W Mb & $88.5 \pm 6.64$ & $162 \pm 21$ & 545,050 \\
F43Y/T67R/P88W/F138W Mb & $76.8 \pm 1.89$ & $60 \pm 4$ & $1,276,570$ \\
HRP [40] & $340 \pm 60$ & $430 \pm 20$ & 800,000 \\
HRP [41] & $332 \pm 18$ & $233 \pm 21$ & $1,420,000$ \\
\hline
\end{tabular}

(A)

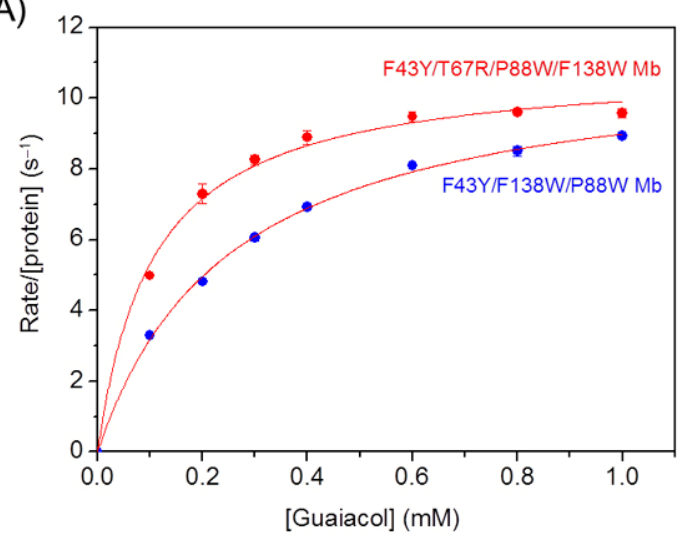

(B)

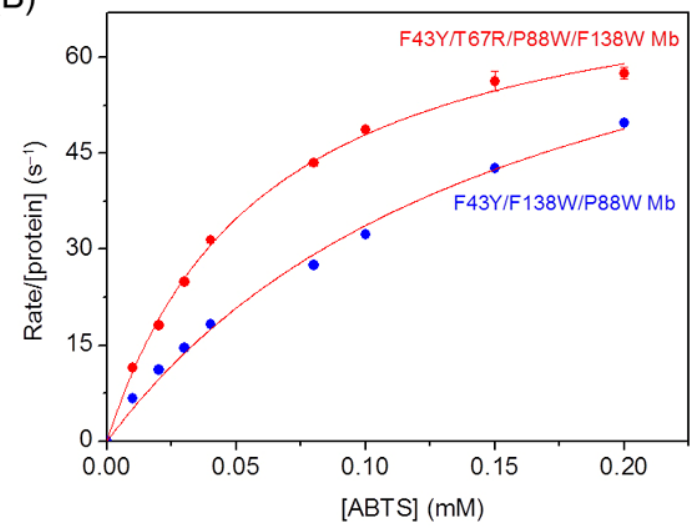

Figure 2. Steady-state rates of $\mathrm{H}_{2} \mathrm{O}_{2}$-dependent oxidation of guaiacol (A) and ABTS (B) catalyzed by F43Y/F138W/P88W Mb and F43Y/T67R/P88W/F138W Mb, with increasing the substrate concentrations. Reaction conditions: $2 \mu \mathrm{M}$ protein, $20 \mathrm{mM} \mathrm{H}_{2} \mathrm{O}_{2}, 50 \mathrm{mM}$ potassium phosphate buffer at $\mathrm{pH}$ 7.0, $25^{\circ} \mathrm{C}$. The data were fitted to the Michaelis-Menten equation.

\subsection{Dye-Decolorizing Peroxidase Activity}

We then evaluated the dye-decolorizing peroxidase activity of the quadruple mutant YRW2 $\mathrm{Mb}$ toward different organic dyes, including malachite green (MG), brilliant blue $R$ (BBR), reactive blue 19 (RB19), reactive black 5 (RB5), amaranth (Ama), and reactive orange 16 (RO16). The experiments were performed on UV-vis spectrophotometer under optimal operational conditions (i.e., $50 \mathrm{mM}$ potassium phosphate buffer, $\mathrm{pH}$ 7.0, with an addition of $5 \mathrm{mM} \mathrm{H}_{2} \mathrm{O}_{2}$ ) and the spectral changes were monitored after incubation for $0.5-1$ h. As shown in Figure 3 and Table S1, the enzyme was able to decolorize all tested dyes. A remarkable dye-decolorizing effect was observed for the triphenylmethane dye, MG, after incubation for $1 \mathrm{~h}(\sim 94 \%$, Figure $3 \mathrm{~A}$ ) albeit with $\sim 54 \%$ for BBR (Figure 3B). This decolorization effect is similar to that observed for the natural enzyme laccase in the decolorization of MG for $24 \mathrm{~h}(\sim 90 \%)$ [42]. Moreover, for the decolorization of anthraquinone dyes such as RB19, the catalytic efficiency achieved $\sim 85 \%$ after incubation for less than 
$10 \mathrm{~s}$ (Figure 3C), which suggests that $\mathrm{YRW} 2 \mathrm{Mb}$ is more reactive toward the decolorization of RB19.

(A)

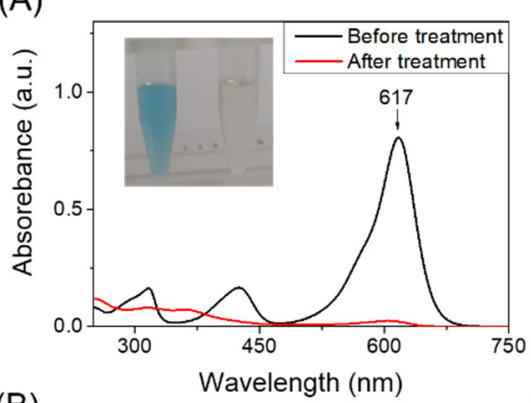

(B)

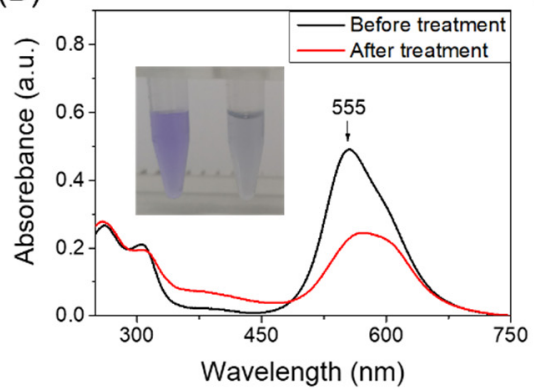

(C)

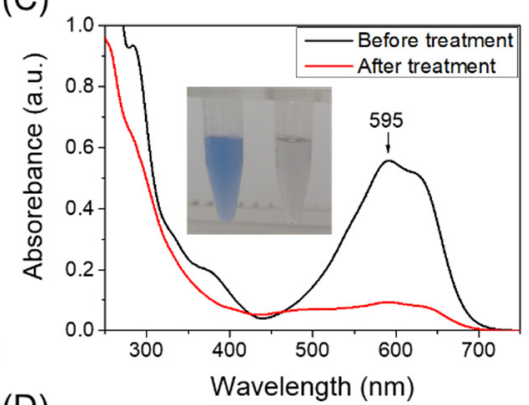

(D)

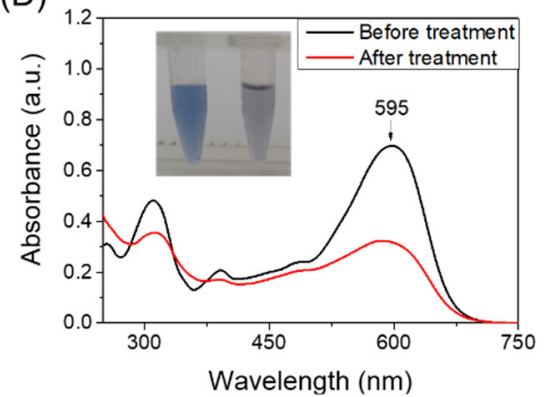

$(\mathrm{E})$

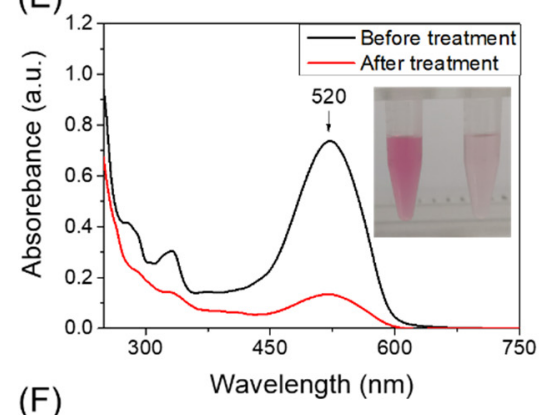

$(F)$

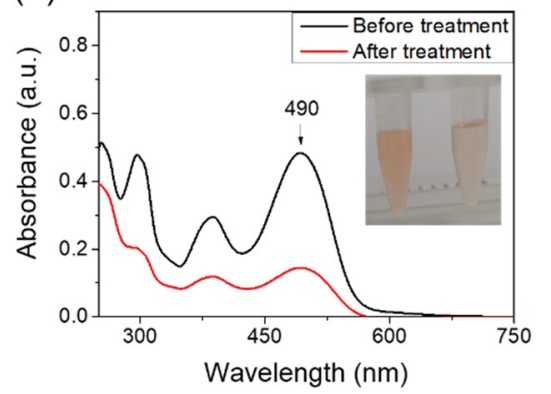

Figure 3. UV-vis absorption spectra of organic dyes before and after treatment by F43Y/T67R/P88W/F138W Mb (5 $\mu \mathrm{M})$ in the presence of $\mathrm{H}_{2} \mathrm{O}_{2}(5 \mathrm{mM})$ : (A) Malachite Green Oxalate $(5 \mu \mathrm{M}),($ B $)$ Brilliant blue R $(20 \mu \mathrm{M})$, (C) Reactive blue $19(60 \mu \mathrm{M}),($ D) Reactive black $5(20 \mu \mathrm{M})$, (E) Amaranth $(20 \mu \mathrm{M})$, and (F) Reactive orange $16(20 \mu \mathrm{M})$.

Further study on the decolorization of double azo dyes, we found that the decolorization effect of YRW2 Mb on RB5 after incubation for $30 \mathrm{~min}(\sim 54 \%$, Figure 3D) was similar to BBR (Figure 3B). Meanwhile, a much higher decolorization effect was observed for the decolorization of single azo dyes, such as Ama ( 82\%, Figure 3E) and RO16 ( 70\%, Figure $3 \mathrm{~F})$, after incubation for $30 \mathrm{~min}$ under the same conditions. These observations agree with a previous report for a white rot bacterium, CBR43, which achieved the maximum decolorization effect for single azo dyes (i.e., 51-80\% decolorization in 9 days) [18]. Therefore, these results suggest that the quadruple mutant YRW2 Mb has potential applications in the decolorization of various types of synthetic dyes.

It should be noted that some of the dyes show different protonation states at $\mathrm{pH} 7.0$, which might affect the decolorization efficiency. It is different from that natural DyPs work at considerably low $\mathrm{pH}$ values ( $\mathrm{pH} 3-4)$ [24], the enzymes designed in Mb work well at $\mathrm{pH} 6-7$, which is thus more environmentally friendly [30,31]. Moreover, these organic dyes have different redox potentials, which may also affect the decolorization activity of the designed heme enzymes [17]. Therefore, further investigation of the relationship should be a future direction.

\subsection{Bioconversion of Kraft Lignin}

Given the complex structure of lignin, there are different options to evaluate the enzyme activity in reaction with lignin. We carried out the experiments on kraft lignin and studied the kinetics of kraft lignin oxidation by monitoring the change of absorbance at $465 \mathrm{~nm}$. As shown in Figure 4A, the oxidation rate catalyzed by YRW2 Mb increased at first $\sim 20 \mathrm{~s}$ and reached a plateau after $\sim 60 \mathrm{~s}$, with an obvious rate constant $\left(k_{\mathrm{obs}}\right)$ of $0.451 \pm 0.013 \mathrm{~s}^{-1}$. Control study using YW2 Mb showed that the reaction rate was considerably slower $\left(k_{\mathrm{obs}}=0.162 \pm 0.003 \mathrm{~s}^{-1}\right.$, Figure 4B), reaching a plateau after $\sim 100 \mathrm{~s}$. The visual appearances upon the oxidation of Kraft lignin were shown in Figure 4A,B (right column), which showed red for the solutions after the treatment of Kraft lignin. 
(A)
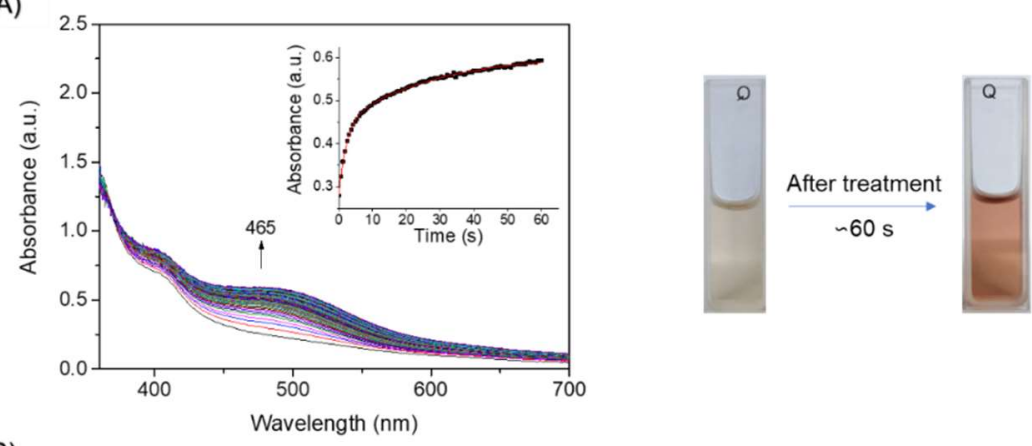

(B)
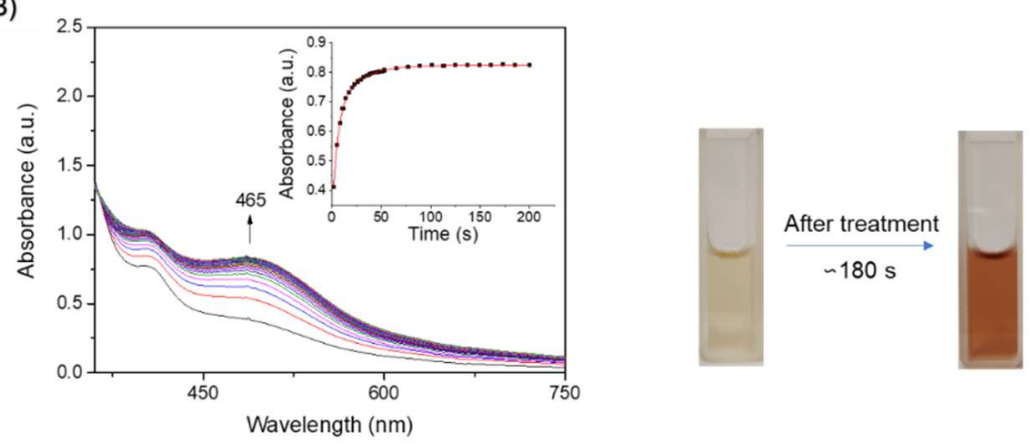

(C)

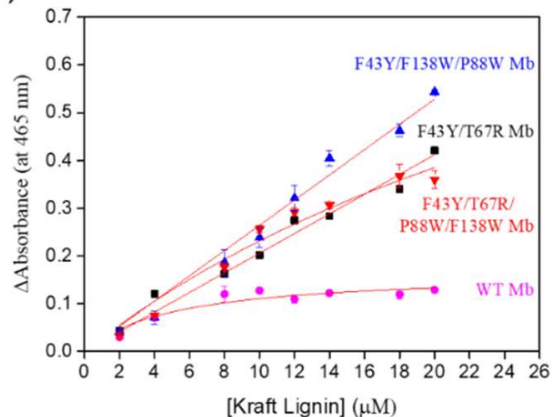

(D)

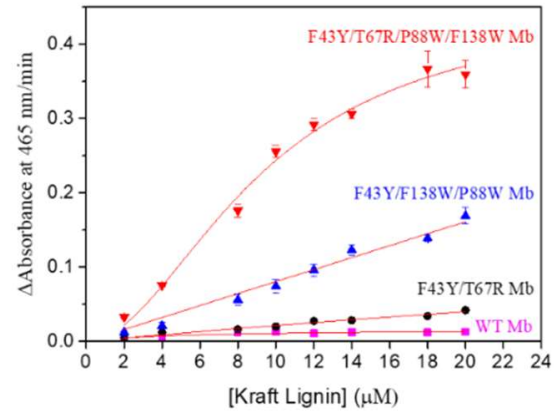

Figure 4. Kinetic studies of Kraft lignin $(14 \mu \mathrm{M})$ oxidation in the presence of $\mathrm{H}_{2} \mathrm{O}_{2}(2.0 \mathrm{mM})$ catalyzed by (A) F43Y/T67R/P88W/F138W Mb $(2 \mu \mathrm{M})$ and (B) F43Y/F138W/P88W Mb $(2 \mu \mathrm{M})$, respectively. Time-dependent changes of the absorbance at $465 \mathrm{~nm}$ were shown as insets and were fitted to the double-exponential decay function. The color changes upon reaction were shown in the right column. (C) The changes of absorbance at $465 \mathrm{~nm}$ after reacting for 1-10 $\mathrm{min}$. (D) steady-state rates of oxidation with different concentrations of Kraft lignin, as catalyzed by F43Y/T67R/P88W/F138W $\mathrm{Mb}, \mathrm{F} 43 \mathrm{Y} / \mathrm{F} 138 \mathrm{~W} / \mathrm{P} 88 \mathrm{~W} \mathrm{Mb}, \mathrm{F} 43 \mathrm{Y} / \mathrm{T} 67 \mathrm{R} \mathrm{Mb}$, and WT Mb, respectively. The plots were fitted to the Hill and Michaelis-Menten equations, respectively. The error bars in C and D were generated from triplicate experiments.

We also studied the dependence of Kraft lignin concentration on enzymatic activity. As shown in Figure 4C, the absorbance at $465 \mathrm{~nm}$ increased with the increase of lignin concentration for the reaction catalyzed by YRW2 Mb. Similar results were observed for the double and triple mutants, F43Y/T67R Mb and YW2 Mb. Further analysis showed that, although the change in absorbance of Kraft lignin catalyzed by YRW2 Mb was not as high as that of YW2 Mb, the catalytic rate of the quadruple mutant $(0.3596 \mathrm{a} . \mathrm{u} / \mathrm{min})$ was $\sim 2$-fold higher compared to that of YW2 Mb (0.1691 a.u./min) (Figure 4D). As compared in Figure 5, the activity is $\sim 8$-fold and $~ 28$-fold higher than F43Y /T67R Mb $(0.0429$ a.u./min) and $\mathrm{WT} \mathrm{Mb}$ (0.0129 a.u./min), respectively [27]. Moreover, the enzymatic activity with $20 \mu \mathrm{M}$ Kraft lignin was $~ 9-17$-fold higher than those reported recently for the natural peroxidase Dyp1B (0.0248 a.u./min) or its mutants S223N (0.0397 a.u./min) and H127R (0.0207 a.u./min) (Figure 5) [43]. These results suggest that YRW2 Mb was efficient in 
catalyzing the bioconversion of Kraft lignin, although it was difficult to analyze the products due to the complexity.

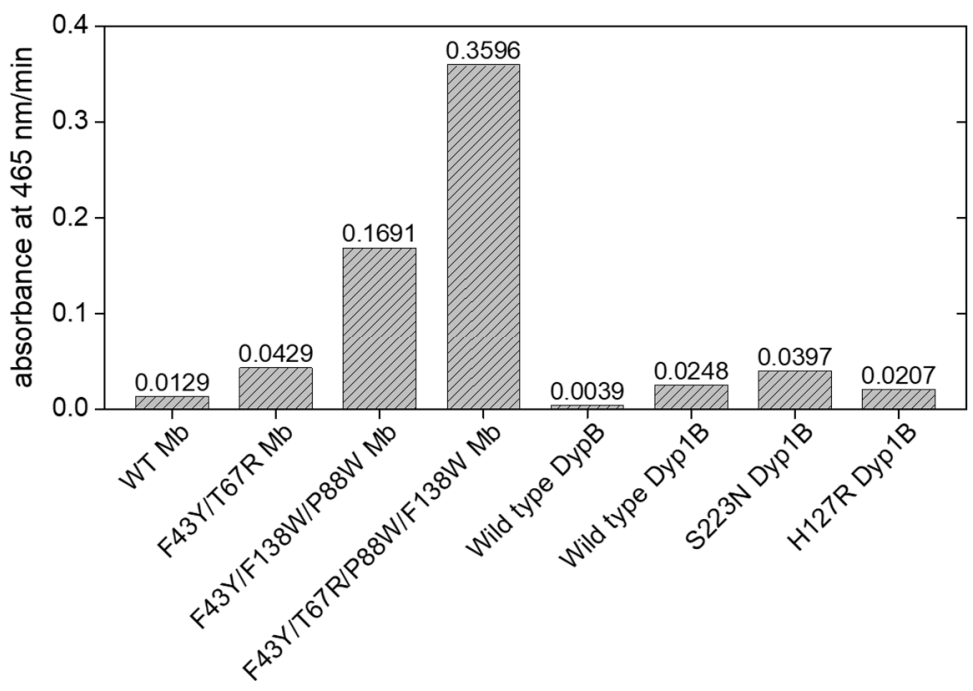

Figure 5. The enzymatic activities for $\mathrm{Mb}$ and its mutants in the oxidation of Kraft lignin, with the native Dyp and its mutants shown for comparison.

\subsection{Bioconversion of Model Compound GGE}

To identify possible products of lignin bioconversion and provide information for the reaction mechanism, we chose to evaluate the oxidation of the lignin model compound, guaiacylglycerol- $\beta$-guaiacyl ether (GGE), a phenolic type model compound containing the $\beta-\mathrm{O}-4$ bond that constitutes $50-70 \%$ of intersubunit bonds in Kraft lignin. At first, we monitored the visual appearance during the oxidation of GGE catalyzed by the quadruple mutant (Figure 6A). The results of an addition-elimination reaction with 2,4-dinitropenylhydrazine (2,4-DNP) indicated that an alcoholic group in GGE was oxidized to a ketone or aldehyde. As shown in Figure 6B, when GGE was oxidized to produce a carbonyl group, it spontaneously reacted with 2,4-DNP in acidic conditions, producing a dinitrophenylhydrazone derivative, which appeared red after reacting with $\mathrm{NaOH}$ [44].

(A)

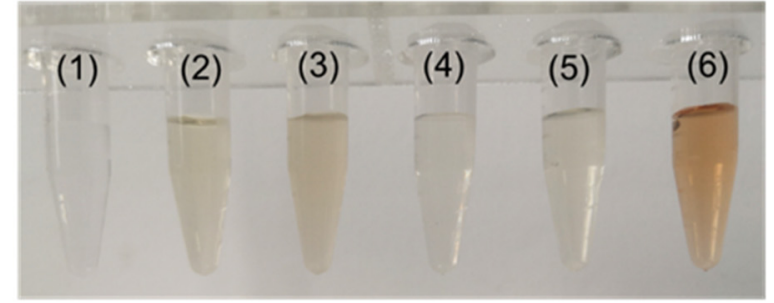

(1) GGE+Buffer

(2) GGE+Buffer+ F43Y/T67R/P88W/F138W Mb

(3) GGE+Buffer+ $\mathrm{H}_{2} \mathrm{O}_{2}+\mathrm{F} 43 \mathrm{Y} / \mathrm{T} 67 \mathrm{R} / \mathrm{P} 88 \mathrm{~W} / \mathrm{F} 138 \mathrm{~W} \mathrm{Mb}$

(4) (1)+2,4-dinitropenylhydrazine $+\mathrm{NaOH}$

(5) (2)+2,4-dinitropenylhydrazine $+\mathrm{NaOH}$

(6) (3)+2,4-dinitropenylhydrazine $+\mathrm{NaOH}$
(B)
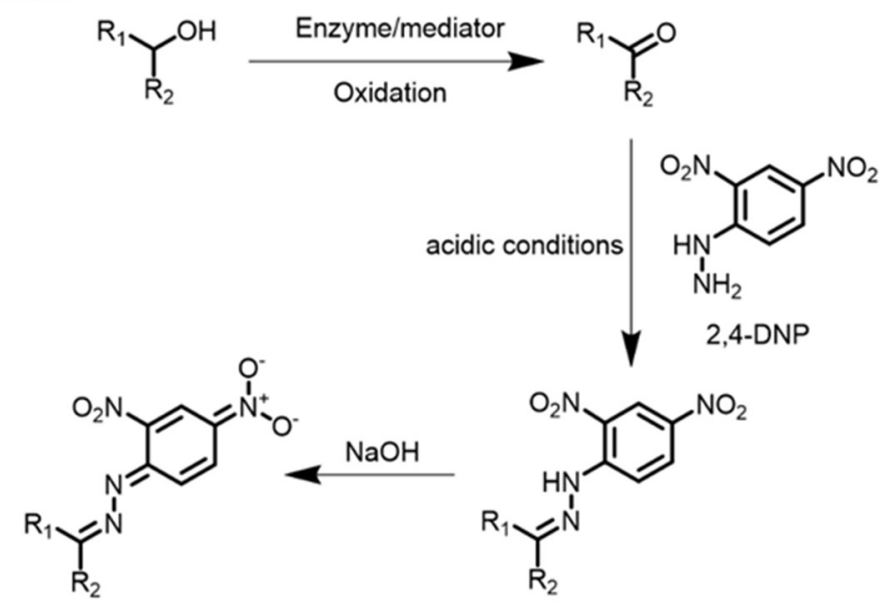

Figure 6. (A) Visual appearance of GGE (2.0 mM) oxidation in the absence (1) and presence (2-3) of $\mathrm{F} 43 \mathrm{Y} / \mathrm{T} 67 \mathrm{R} / \mathrm{P} 88 \mathrm{~W} / \mathrm{F} 138 \mathrm{~W} \mathrm{Mb}(5 \mu \mathrm{M})$ and $\mathrm{H}_{2} \mathrm{O}_{2}(2.0 \mathrm{mM})$ (3) for $10 \mathrm{~min}$. After the reactions (1), (2), and (3) mixed with 2,4-dinitropenylhydrazine (2,4-DNP, $0.3 \mathrm{mM}$ ) for $15 \mathrm{~min}$, the visual appearance of reactions in the presence (4-6) of $\mathrm{NaOH}(0.5 \mathrm{mM})$. (B) Reaction overview of 2,4-DNP with carbonyl groups [44]. 
After the assays, the resulting solutions appeared yellow in the treatment of GGE by YRW2 $\mathrm{Mb}$ in the presence of $\mathrm{H}_{2} \mathrm{O}_{2}$ (Figure 6, entry 3), which was not observed for buffer solution containing GGE in the absence or presence of the enzyme (Figure 6, entries 1-2). After the addition of 2,4-DNP and $\mathrm{NaOH}$ to the buffer containing GGE in the absence or presence of $\mathrm{H}_{2} \mathrm{O}_{2}$ and the enzyme, the results showed that in the presence of $\mathrm{H}_{2} \mathrm{O}_{2}$, the product of GGE catalyzed by enzyme reacted with 2,4-DNP and showed red for the solution (Figure 6, entry 6). Therefore, this colorimetric assay suggests that GGE oxidation was coupled to its depolymerization, and the products were further analyzed in the following sections.

\subsection{HPLC and ESI-MS Analysis of the Products}

To analyze the oxidation products of the dimeric lignin model GGE, we performed both HPLC and mass spectrometry analysis. As shown in Figure 7A for HPLC analysis, the oxidation of GGE catalyzed by YRW2 Mb resulted in a $\sim 65 \%$ conversion after reacting for $0.5 \mathrm{~h}$ at $\mathrm{pH} 7.0$, and the yield remained similar up to $5 \mathrm{~h}$. Previous studies showed that other natural or artificially modified enzymes can also only oxidize GGE to $60-70 \%$, such as lignin peroxidase from P. eryngii and the PpDyP 6E10 variant from P. putida MET94 [21,45]. Note that the signal of the remaining GGE was observed at 6.607 min in the HPLC trace (Figure 7B).

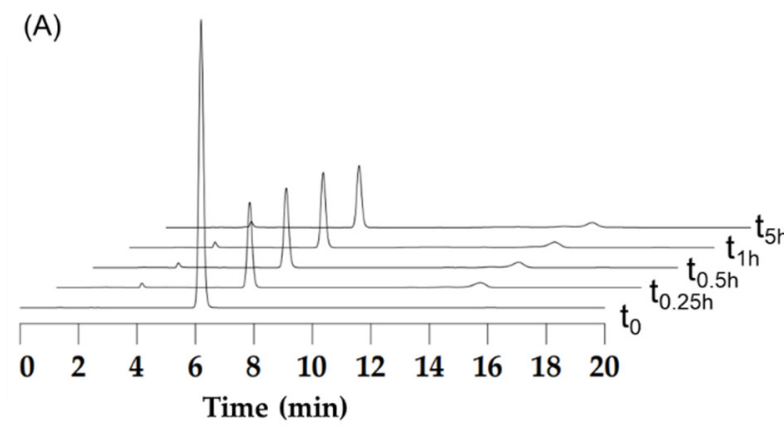

(B)<smiles>COc1cc(C(O)C(CO)Oc2ccccc2OC)ccc1O</smiles>

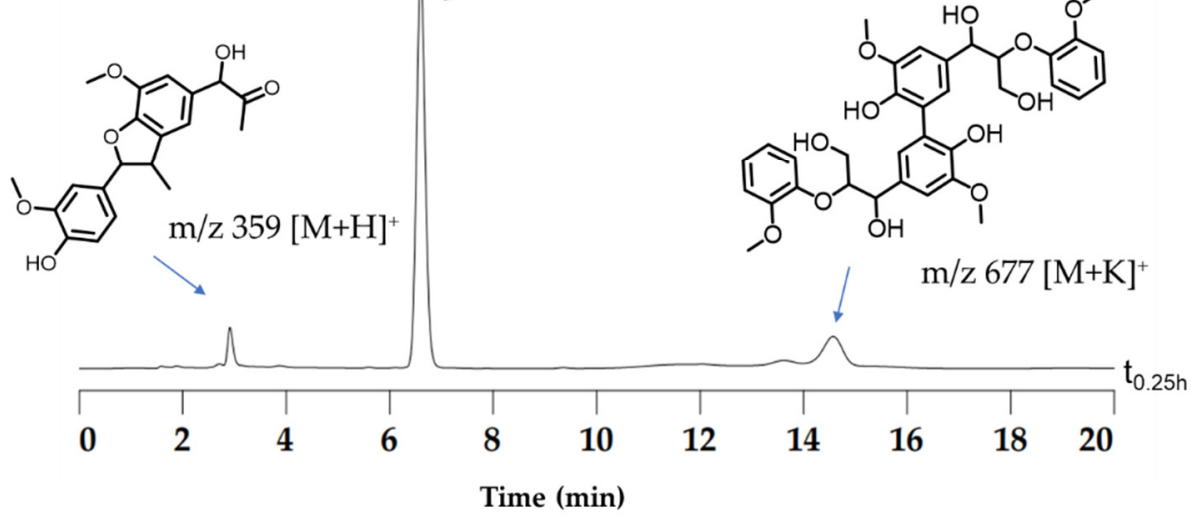

Figure 7. (A) HPLC traces as monitored at $280 \mathrm{~nm}$, showing the oxidation of $2.5 \mathrm{mM}$ of GGE catalyzed by F43Y/T67R/P88W/F138W Mb $(5 \mu \mathrm{M})$ in the presence of $\mathrm{H}_{2} \mathrm{O}_{2}(2 \mathrm{mM})$ in potassium phosphate buffer (pH 7.0). (B) Analysis of the products by mass spectrometry in positive mode, showing $\mathrm{m} / \mathrm{z}$ $359[\mathrm{M}+\mathrm{H}]^{+}$and $677[\mathrm{M}+\mathrm{K}]^{+}$.

The corresponding ESI-MS results revealed the product peaks in a range of $m / z 260-700$, which were higher than the molecular weight of the starting GGE (320 Da, observed, $343 \mathrm{Da}$, $[\mathrm{M}+\mathrm{Na}]^{+}$) (Figure 8A). After reacting for $15 \mathrm{~min}$, we detected the formation of two products by HPLC with retention times (RT) of $2.919 \mathrm{~min}$ and $14.554 \mathrm{~min}$, respectively (Figure 7B). 
Moreover, ESI-MS analysis showed that the molecular weights of the two products were $\mathrm{m} / \mathrm{z}$ 359 and $677 \mathrm{Da}$ (Figure 8B), which are consistent with the molecular formulas of $\mathrm{C}_{20} \mathrm{H}_{22} \mathrm{O}_{6}$ and $\mathrm{C}_{34} \mathrm{H}_{38} \mathrm{O}_{12}$, respectively. Note that the product with a retention time of 14.554 min was a dimer of GGE, which is similar to the HPLC-MS result of the oxidized GGE product as catalyzed by PpDyP 6E10 variant [21].

(A)

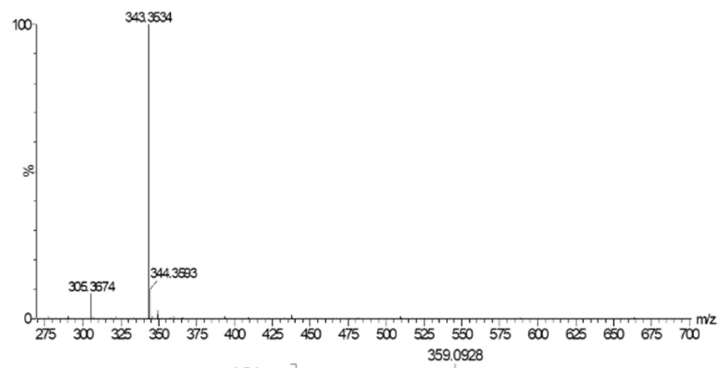

(C)

(D)

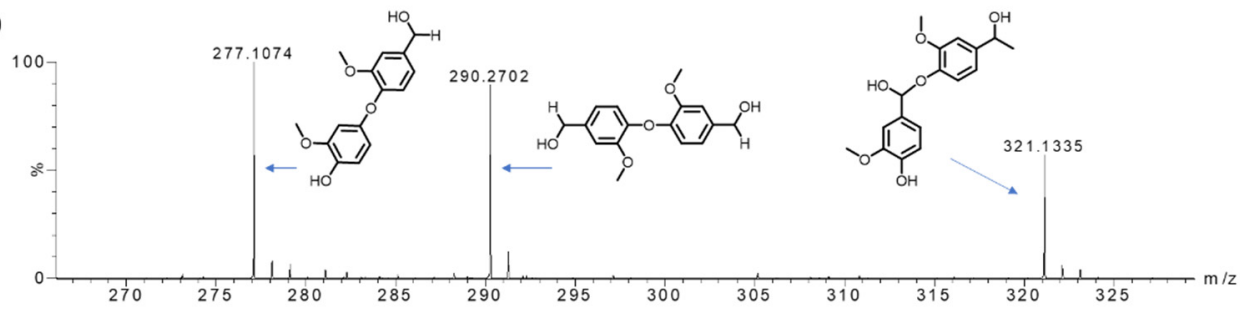

(E)
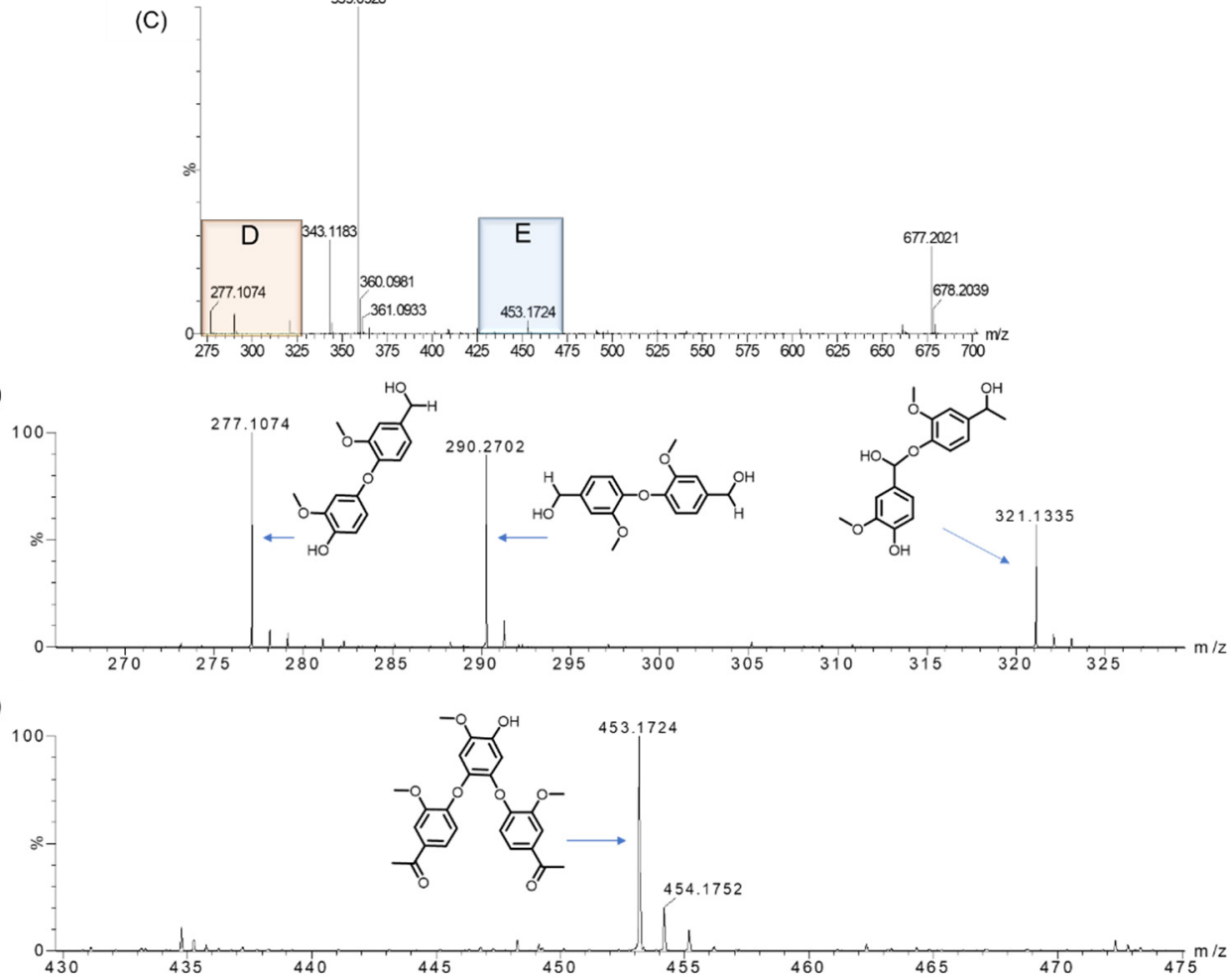

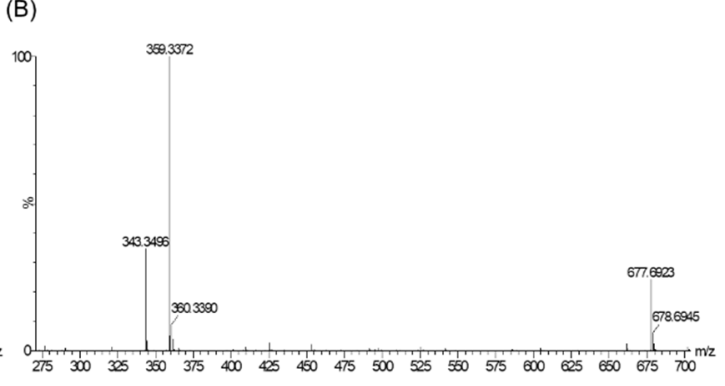

Figure 8. (A) ESI-MS spectra of the GGE with the molecular weight of 343 Da. (B) After reacting for $0.25 \mathrm{~h}$, two major products were detected with molecular weights of 359 and $677 \mathrm{Da}$, respectively. (C) After reacting for $1 \mathrm{~h}$, four more products were detected, with molecular weights of 277, 290, 321 (D), and $453 \mathrm{Da}(\mathrm{E})$.

Moreover, despite only two major product peaks in the HPLC trace after $0.25 \mathrm{~h}$ (Figure 7B), ESI-MS analysis showed that four product peaks appeared in the D and E regions after reacting for $1 \mathrm{~h}$ (Figure $8 \mathrm{C}$ ). This might be due to the low content of the product that was below the detection limit of HPLC. As shown in Figure 8D,E for these two regions, these mass signals showed $m / z 277[\mathrm{M}+\mathrm{H}]^{+}, 290[\mathrm{M}]^{+}, 321[\mathrm{M}+\mathrm{H}]^{+}$, and $453[\mathrm{M}+\mathrm{H}]^{+}$, which are consistent with the molecular formulas of $\mathrm{C}_{15} \mathrm{H}_{16} \mathrm{O}_{5}, \mathrm{C}_{16} \mathrm{H}_{18} \mathrm{O}_{5}$, $\mathrm{C}_{17} \mathrm{H}_{20} \mathrm{O}_{6}$, and $\mathrm{C}_{25} \mathrm{H}_{24} \mathrm{O}_{8}$, respectively. These results indicate that as catalyzed by YRW2 $\mathrm{Mb}$, the main GGE degradation patterns were caused by the oxidative cleavage of the C-C or C-O bond, which produced small molecules such as those detected with molecular weights of 277, 290, 321, and 453 Da. These products may further undergo polymerization, as proposed in the following section. 


\subsection{Proposed Mechanism for GGE Bioconversion}

Based on the above HPLC and ESI-MS results, we proposed a generation route of the reaction products, which may involve the generation of reactive radical species upon the activation of $\mathrm{H}_{2} \mathrm{O}_{2}$ by the heme enzymes [13,19,30,46,47], resulting in various types of bond cleavages. As shown in Figure 9, for the oxidative cleavage, the monomers can hardly exist alone, and they might be recombined into new species. For example, by $\mathrm{C} \alpha-\mathrm{C} \beta$ cleavage of GGE, product 1 (4-(hydroxymethyl)-2-methoxyphenol) will be generated, which further forms a dimer, matching the expected molecular formulas of $\mathrm{C}_{16} \mathrm{H}_{18} \mathrm{O}_{5}$, with a molecular weight of $290[\mathrm{M}]^{+}$. The reaction will also produce product 2 (guaiacol) by the cleavage of aryl-O-C $\beta$ bond in GGE. Note that products 1 and 2 may be coupled to form a heterodimer, with an expected molecular formula of $\mathrm{C}_{15} \mathrm{H}_{16} \mathrm{O}_{5}$ and $m / z 277[\mathrm{M}+\mathrm{H}]^{+}$. A previous study showed that the degradation of GGE by TcDyP also produced the product of guaiacol, whereas it ultimately formed guaiacol pentamer [24].

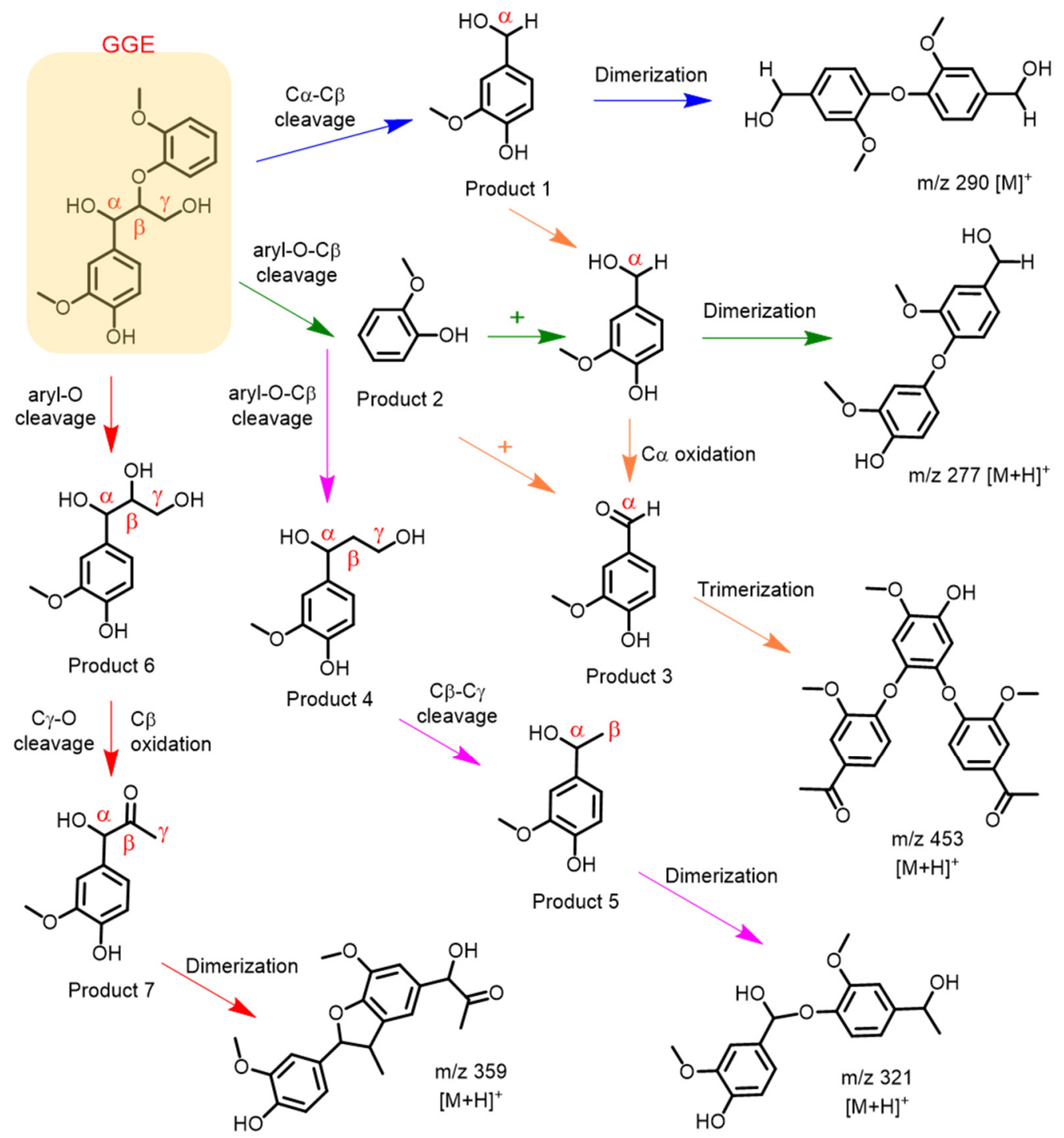

Figure 9. Depolymerization and polymerization of the GGE catalyzed by F43Y/F138W/P88W/T67R $\mathrm{Mb}$. Product $\mathbf{1}$ is 4 -(hydroxymethyl)-2-methoxyphenol, product $\mathbf{2}$ is guaiacol, product 3 is vanillin, product 4 is 1-(4-hydroxy-3-methoxyphenyl)propane-1,3-diol, product 5 is 4-(1-hydroxyethyl)- 2methoxyphenol, product 6 is 1-(4-hydroxy-3-methoxyphenyl)propane-1,2,3-triol, and product 7 is 1-hydroxy-1-(4-hydroxy-3-methoxyphenyl)propan-2-one, respectively. 
Moreover, after the $\mathrm{C} \alpha-\mathrm{C} \beta$ or aryl-C $\alpha$ cleavage of GGE, the reaction may continue to generate product 3 (vanillin) by oxidation of $\mathrm{C} \alpha$. Then products 2 and 3 may form a heterotrimer linked by C-O-C bonds, generating the observed molecule of $\mathrm{C}_{25} \mathrm{H}_{24} \mathrm{O}_{8}$ with $\mathrm{m} / z 453[\mathrm{M}+\mathrm{H}]^{+}$. It should be noted that the detection of vanillin from a lignin dimer was reported previously for $R$. jostii $\mathrm{DypB}$, which revealed that the oxidative cleavage of $C \alpha-C \beta$ occurred, although dimerization via the coupling of phenoxy radicals also occurred [48].

As shown in Figure 9, upon the aryl-O-C $\beta$ cleavage of GGE, in addition to product 2, the depolymerization product 4, (1-(4-hydroxy-3-methoxyphenyl)propane-1,3-diol), may also be generated. It will be further cleaved by $C \beta-C \gamma$ to produce product 5, (4-(1hydroxyethyl)-2-methoxyphenol). Product 5 may undergo dimerization to form a dimer, with the molecular formula of $\mathrm{C}_{17} \mathrm{H}_{20} \mathrm{O}_{6}$. Alternatively, GGE may be cleaved by the aryl-O bond, producing product 6, (1-(4-hydroxy-3-methoxyphenyl)propane- 1,2,3-triol). Furthermore, it will produce product 7, (1-hydroxy-1-(4-hydroxy-3- methoxyphenyl)propan-2-one), by both $C \gamma$-O cleavage and $C \beta$ oxidation of product 6 , which will also form a dimer, with a molecular weight corresponding to the molecular formula of $\mathrm{C}_{20} \mathrm{H}_{22} \mathrm{O}_{6}(\mathrm{~m} / z$ 359) that has an $\mathrm{RT}$ of $2.919 \mathrm{~min}$. Based on these proposed degradation pathways for the model compound GGE, we can infer the possibility that YRW2 Mb could attack at the corresponding catalytic cracking sites of Kraft lignin in bioconversion.

\section{Materials and Methods}

\subsection{Materials}

Malachite green (MG), Brilliant blue R (BBR), Reactive blue 19 (RB19), Reactive black 5 (RB5), amaranth (Ama), and Reactive orange 16 (RO16) were bought from Adamas-beta (Shanghai, China). The peroxidase substrates, guaiacol, and 2,2'-azino-bis (3-ethylbenzothiazoline-6sulfonic acid) diammonium salt (ABTS) were bought from Aladdin Industrial Corporation (Shanghai, China). Guaiacylglycerol- $\beta$-guaiacyl ether (GGE) was purchased from Shanghai Macklin Biochemical Co., Ltd. (Shanghai, China). 2,4-dinitrophenylhydrazine (2,4-DNP) were bought from Adamas-beta. Lignin and alkali (Lignin, Kraft) were bought from Sigma-Aldrich (Saint Louis, MO, USA). All other reagents were of analytical grade.

\subsection{Protein Expression and Purification}

WT sperm whale $\mathrm{Mb}$ was expressed in the host E. coli BL21(DE3) cells transformed with the pMbt7-7-Mb plasmid [49]. The gene of F43Y/T67R/P88W/F138W Mb (YRW2 Mb) was constructed by the QuikChange Site-Directed Mutagenesis Kit (Stratagene, Inc. Santa Clara, CA, USA) using the WT Mb gene as a template, and the mutations were identified by DNA sequencing. The quadruple mutant $\mathrm{YRW} 2 \mathrm{Mb}$ was expressed and purified using the same procedure as previously reported [31], which was further confirmed by ESI-MS analysis (Figure S1). The $\mathrm{H}_{2} \mathrm{O}_{2}$-dependent of the peroxidase activities were performed under similar conditions by varying the concentrations of $\mathrm{H}_{2} \mathrm{O}_{2}(0 \sim 25 \mathrm{mM})$ (Figure S2).

\subsection{Peroxidase Activity Assay}

The kinetic parameters for the peroxidase activity of YRW2 Mb were investigated on a dual mixing stopped-flow spectrophotometer (SF-61DX2 Hi-Tech KinetAsystTM) (Hi-Tech Scientific, Bradford-on-Avon, UK) using guaiacol $\left(0-1.0 \mathrm{mM}, \varepsilon_{470 \mathrm{~nm}}=26.6 \mathrm{mM}^{-1}\right.$ $\left.\mathrm{cm}^{-1}\right)$ or ABTS $\left(0-0.2 \mathrm{mM}, \varepsilon_{660 \mathrm{~nm}}=14 \mathrm{mM}^{-1} \mathrm{~cm}^{-1}\right)$ as the substrate, in $50 \mathrm{mM}$ potassium phosphate buffer, $\mathrm{pH} 7.0,25^{\circ} \mathrm{C}$, to which $\mathrm{H}_{2} \mathrm{O}_{2}(20 \mathrm{mM})$ was added. Control experiments were performed with the triple mutant $\mathrm{F} 43 \mathrm{Y} / \mathrm{F} 138 \mathrm{~W} / \mathrm{P} 88 \mathrm{~W} \mathrm{Mb}(\mathrm{YW} 2 \mathrm{Mb})$ under the same conditions.

\subsection{Dye-Decolorizing Peroxidase Activity Assay}

The synthetic dyes MG, BBR, RB19, RB5, Ama, and RO16 were used to evaluate the decolorization capability of YRW2 Mb. The reaction mixture contained 5-60 $\mu \mathrm{M}$ dye and $5 \mu \mathrm{M}$ YRW2 $\mathrm{Mb}$, to which $5 \mathrm{mM} \mathrm{H}_{2} \mathrm{O}_{2}$ was added (final volume, $2 \mathrm{~mL}$ ), in $50 \mathrm{mM}$ potassium phosphate buffer, $\mathrm{pH}$ 7.0. After incubation for $0.5-1 \mathrm{~h}$ at room temperature on 
a rotary wheel, the absorbance spectra were recorded from 250 to $750 \mathrm{~nm}$ on a Lambda 365 spectrophotometer (PerkinElmer, Inc., Waltham, MA, USA). The control experiments were performed under the same conditions without the addition of the enzyme. The dye decolorization was expressed in percentage as follows $[18,50]$ :

Dec- $1=[($ Abst0 - Abst 1$)] /$ Abst0 $\times 100$, where Dec-1 is the decolorization level (\%), and Abst 0 and Abst1 are the absorbance values before and after treatment, recorded at 617, 555, 595, 595, 520, and $490 \mathrm{~nm}$ for MG, BBR, RB19, RB5, Ama, and RO16 dyes, respectively.

\subsection{Kinetic Analysis of Alkali Kraft Lignin}

Kraft lignin $(10 \mathrm{mg})$ was dissolved in DMSO $(1 \mathrm{~mL}) .14 \mu \mathrm{M}$ of the sample, $2 \mu \mathrm{M}$ YW2 $\mathrm{Mb}$ or $\mathrm{YRW} 2 \mathrm{Mb}$, and $2 \mathrm{mM} \mathrm{H}_{2} \mathrm{O}_{2}$ were mixed in potassium phosphate buffer ( $\mathrm{pH} 7.0$, $50 \mathrm{mM})$ containing DMSO $(5 \%, v / v)$, with a final volume of $2 \mathrm{~mL}$. The spectrum was monitored for 1-10 min at $465 \mathrm{~nm}$ on an Agilent 8453 diode array spectrometer (Agilent Technologies, Inc., Santa Clara, CA, USA) or a stopped-flow spectrophotometer. Substrate concentrations were then varied for Kraft lignin (final concentration, 2-20 $\mu \mathrm{M}$ ), with the total volume kept at $2 \mathrm{~mL}$. The concentration was calculated using an average molecular mass of 10,000 Da.

\subsection{Assay for Ketone Products}

Upon oxidation of GGE catalyzed by YRW2 Mb, for detecting any released aldehydes or ketones molecules, an assay was used based on the reaction of aldehydes with 2,4-DNP, which forms a colored hydrazone product [44]. Briefly, 2.0 mM GGE dissolved in $1 / 1$ ethanol $/ \mathrm{H}_{2} \mathrm{O}$ was added to the potassium phosphate buffer $(2 \mathrm{~mL}, 50 \mathrm{mM}, \mathrm{pH}$ 7.0), followed by the addition of YRW2 $\mathrm{Mb}$ and $\mathrm{H}_{2} \mathrm{O}_{2}(2 \mathrm{mM})$. The resulting solution was incubated at $25^{\circ} \mathrm{C}$ for $1 \mathrm{~h}$. Then, $200 \mu \mathrm{L}$ of the solution was mixed with $300 \mu \mathrm{L} \mathrm{HCl}$ $(100 \mathrm{mM})$ followed by the addition of $500 \mu \mathrm{L}$ of $2,4-\mathrm{DNP}(1 \mathrm{mM}$ dissolved in $100 \mathrm{mM} \mathrm{HCl})$. The mixture was incubated at $25^{\circ} \mathrm{C}$ for $5 \mathrm{~min}$ and then $1000 \mu \mathrm{L} \mathrm{NaOH}(100 \mathrm{mM})$ was added, as described previously [51].

\subsection{HPLC and Mass Spectrometry}

A $20 \mathrm{mM}$ GGE solution was prepared by dissolving $25 \mathrm{mg}$ of the substrate in $1 \mathrm{~mL}$ ethanol and diluted to a final volume of $2 \mathrm{~mL}$ with water. The assay mixture containing $50 \mathrm{mM}$ potassium phosphate buffer, $\mathrm{pH}$ 7.0, $2.5 \mathrm{mM} \mathrm{GGE}, 2 \mathrm{mM} \mathrm{H}_{2} \mathrm{O}_{2}$, and $5 \mu \mathrm{M} \mathrm{YRW2}$ $\mathrm{Mb}$ was incubated at $25^{\circ} \mathrm{C}$ (final volume, $2.0 \mathrm{~mL}$ ). At fixed times, $300 \mu \mathrm{L}$ of the reaction solution was added with $100 \mu \mathrm{L}$ of acetonitrile, followed by passing the $0.22 \mathrm{~mm}$ filter membrane. $20 \mu \mathrm{L}$ of the filtrate was analyzed by HPLC analysis using a Shim-pack GIST $5 \mu \mathrm{m}$ C18 column (150/4.6 mm), detection set at $280 \mathrm{~nm}$. Elution gradient: $0-20 \mathrm{~min}, 30 \%$ acetonitrile $/ 70 \% \mathrm{H}_{2} \mathrm{O}$. The retention times (RT) of GGE were $6.607 \mathrm{~min}$. The remaining filtrate was carried out on G2-XS QTOF mass spectrometry (Waters, Milford, MA, USA), and the samples were transferred into the mass spectrometer chamber for measurement under a positive mode.

\section{Conclusions}

Inspired by the key structural feature of natural heme enzymes, in this study we rationally designed an efficient peroxidase using $\mathrm{Mb}$ as a protein model, by introducing both the conserved His-Arg pair for catalysis and the Tyr/Trp for electron transfer in the heme active site. Kinetic studies showed that the designed quadruple mutant F43Y/T67R/P88W/F138W Mb exhibits remarkable peroxidase activity, with the catalytic efficiency similar to that of the most efficient natural enzyme HRP. The quadruple mutant is also able to decolorize multiple types of synthetic textile dyes, including triphenylmethanetype dyes, azo-type dyes, and anthraquinone-type dyes. Moreover, this enzyme exhibits a potential for bioconversion of lignin, such as Kraft lignin and the model lignin dimer GGE, representative of the main-chain linkages in lignin. By analysis using HPLC and ESI-MS, we identified several bioconversion products of GGE, as produced via $\mathrm{C} \alpha-\mathrm{C} \beta$, aryl-C $\alpha$, 
aryl-O-C $\beta, C \beta-C \gamma$, or $C \beta-O$ cleavage, followed by dimerization or trimerization, which illustrates the mechanism for the bioconversion of lignin. This study indicates that the rationally designed F43Y/T67R/P88W/F138W Mb is an efficient multi-functional peroxidase, which could thus be exploited for the decolorization of textile wastewater contaminated with various dyes, as well as for the bioconversion of lignin from the industry to produce more value-added products.

Supplementary Materials: The following are available online at https:/ /www.mdpi.com/article/10 .3390/ijms23010413/s1.

Author Contributions: Conceptualization, Y.-W.L.; methodology, W.-J.G., J.-K.X. and S.-T.W.; validation, Y.-W.L.; investigation, W.-J.G., J.-K.X., S.-T.W. and S.-Q.G.; data curation, W.-J.G., J.-K.X., S.-T.W. and S.-Q.G.; writing-original draft preparation, W.-J.G. and J.-K.X.; writing-review and editing, Y.-W.L.; supervision, Y.-W.L.; project administration, Y.-W.L., G.-B.W. and X.T.; funding acquisition, Y.-W.L., J.-K.X. and X.T. All authors have read and agreed to the published version of the manuscript.

Funding: This research was funded by the National Natural Science Foundation of China (32171270, 21977042, 21977017 and 32171263), Special Project of Major Scientific and Technological Innovation in Shandong Province (2018SDKJ0303-1-3) and Postgraduate Scientific Research Innovation Project of Hunan Province (CX20210919).

Data Availability Statement: The datasets for this manuscript can be obtained from the corresponding author upon reasonable request.

Acknowledgments: We thank S. G. Sligar and Y. Lu (University of Illinois at Urbana-Champaign, USA) for providing the sperm whale $\mathrm{Mb}$ gene.

Conflicts of Interest: The authors declare no conflict of interest.

\section{References}

1. Ali, S.; Peter, A.P.; Chew, K.W.; Munawaroh, H.S.H.; Show, P.L. Resource recovery from industrial effluents through the cultivation of microalgae: A review. Bioresour. Technol. 2021, 337, 125461. [CrossRef] [PubMed]

2. Andersson, E.; Dernegard, H.; Wallen, M.; Thollander, P. Decarbonization of industry: Implementation of energy performance indicators for successful energy management practices in kraft pulp mills. Energy Rep. 2021, 7, 1808-1817. [CrossRef]

3. Sosa-Martinez, J.D.; Balagurusamy, N.; Montanez, J.; Peralta, R.A.; Moreira, R.D.P.M.; Bracht, A.; Peralta, R.M.; Morales-Oyervides, L. Synthetic dyes biodegradation by fungal ligninolytic enzymes: Process optimization, metabolites evaluation and toxicity assessment. J. Hazard. Mater. 2020, 400, 123254. [CrossRef] [PubMed]

4. Singh, A.K.; Bilal, M.; Iqbal, H.M.N.; Meyer, A.S.; Raj, A. Bioremediation of lignin derivatives and phenolics in wastewater with lignin modifying enzymes: Status, opportunities and challenges. Sci. Total Environ. 2021, 777, 145988. [CrossRef]

5. Gogate, P.R.; Pandit, A.B. A review of imperative technologies for wastewater treatment I: Oxidation technologies at ambient conditions. Adv. Environ. Res. 2004, 8, 501-551. [CrossRef]

6. Brebu, M.; Vasile, C. Thermal degradation of lignin-A Review. Cellul. Chem. Technol. 2010, 44, $353-363$.

7. Zhou, X.F. Conversion of kraft lignin under hydrothermal conditions. Bioresour. Technol. 2014, 170, 583-586. [CrossRef]

8. Lin, Y.-W. Rational design of metalloenzymes: From single to multiple active sites. Coord. Chem. Rev. 2017, 336, 1-27. [CrossRef]

9. Yin, L.-L.; Yuan, H.; Liu, C.; He, B.; Gao, S.-Q.; Wen, G.-B.; Tan, X.; Lin, Y.-W. A Rationally Designed Myoglobin Exhibits a Catalytic Dehalogenation Efficiency More than 1000-Fold That of a Native Dehaloperoxidase. ACS Catal. 2018, 8, 9619-9624. [CrossRef]

10. Nastri, F.; D’Alonzo, D.; Leone, L.; Zambrano, G.; Pavone, V.; Lombardi, A. Engineering Metalloprotein Functions in Designed and Native Scaffolds. Trends Biochem. Sci. 2019, 44, 1022-1040. [CrossRef]

11. Lin, Y.-W. Rational design of heme enzymes for biodegradation of pollutants toward a green future. Biotechnol. Appl. Biochem. 2020, 67, 484-494. [CrossRef]

12. Lin, Y.-W. Biodegradation of aromatic pollutants by metalloenzymes: A structural-functional-environmental perspective. Coord. Chem. Rev. 2021, 434, 213774. [CrossRef]

13. Chen, S.-F.; Liu, X.-C.; Xu, J.-K.; Li, L.; Lang, J.-J.; Wen, G.-B.; Lin, Y.-W. Conversion of Human Neuroglobin into a Multifunctional Peroxidase by Rational Design. Inorg. Chem. 2021, 60, 2839-2845. [CrossRef]

14. Cajnko, M.M.; Oblak, J.; Grilc, M.; Likozar, B. Enzymatic bioconversion process of lignin: Mechanisms, reactions and kinetics. Bioresour. Technol. 2021, 340, 125655. [CrossRef]

15. Chatha, S.A.S.; Asgher, M.; Iqbal, H.M.N. Enzyme-based solutions for textile processing and dye contaminant biodegradation-a review. Environ. Sci. Pollut. Res. Int. 2017, 24, 14005-14018. [CrossRef] 
16. Xu, H.; Guo, M.Y.; Gao, Y.H.; Bai, X.H.; Zhou, X.W. Expression and characteristics of manganese peroxidase from Ganoderma lucidum in Pichia pastoris and its application in the degradation of four dyes and phenol. BMC Biotechnol. 2017, 17, 19. [CrossRef]

17. Jenkins, J.M.X.; Noble, C.E.M.; Grayson, K.J.; Mulholland, A.J.; Anderson, J.L.R. Substrate promiscuity of a de novo designed peroxidase. J. Inorg. Biochem. 2021, 217, 111370. [CrossRef]

18. Yang, S.O.; Sodaneath, H.; Lee, J.I.; Jung, H.; Choi, J.H.; Ryu, H.W.; Cho, K.S. Decolorization of acid, disperse and reactive dyes by Trametes versicolor CBR43. J. Environ. Sci. Health A Tox. Hazard. Subst. Environ. Eng. 2017, 52, 862-872. [CrossRef]

19. Chan, J.C.; Paice, M.; Zhang, X. Enzymatic Oxidation of Lignin: Challenges and Barriers Toward Practical Applications. Chem CatChem 2019, 12, 401-425. [CrossRef]

20. Colpa, D.I.; Fraaije, M.W.; van Bloois, E. DyP-type peroxidases: A promising and versatile class of enzymes. J. Ind. Microbiol. Biot. 2014, 41, 1-7. [CrossRef]

21. Brissos, V.; Tavares, D.; Sousa, A.C.; Robalo, M.P.; Martins, L.O. Engineering a Bacterial DyP-Type Peroxidase for Enhanced Oxidation of Lignin-Related Phenolics at Alkaline pH. ACS Catal. 2017, 7, 3454-3465. [CrossRef]

22. Rahmanpour, R.; Rea, D.; Jamshidi, S.; Fulop, V.; Bugg, T.D.H. Structure of Thermobifida fusca DyP-type peroxidase and activity towards Kraft lignin and lignin model compounds. Arch. Biochem. Biophys. 2016, 594, 54-60. [CrossRef]

23. Chaplin, A.K.; Wilson, M.T.; Worrall, J.A.R. Kinetic characterisation of a dye decolourising peroxidase from Streptomyces lividans: New insight into the mechanism of anthraquinone dye decolourisation. Dalton. Trans. 2017, 46, 9420-9429. [CrossRef]

24. Chen, C.; Shrestha, R.; Jia, K.; Gao, P.F.; Geisbrecht, B.V.; Bossmann, S.H.; Shi, J.; Li, P. Characterization of Dye-decolorizing Peroxidase (DyP) from Thermomonospora curvata Reveals Unique Catalytic Properties of A-type DyPs. J. Biol. Chem. 2015, 290, 23447-23463. [CrossRef]

25. Yan, D.J.; Li, W.; Xiang, Y.; Wen, G.B.; Lin, Y.W.; Tan, X.S. A Novel Tyrosine-Heme C-O Covalent Linkage in F43Y Myoglobin: A New Post-translational Modification of Heme Proteins. Chembiochem 2015, 16, 47-50. [CrossRef]

26. Liu, C.; Yuan, H.; Liao, F.; Wei, C.W.; Du, K.J.; Gao, S.Q.; Tan, X.; Lin, Y.W. Unique Tyr-heme double cross-links in F43Y/T67R myoglobin: An artificial enzyme with a peroxidase activity comparable to that of native peroxidases. Chem. Commun. 2019, 55, 6610-6613. [CrossRef]

27. Guo, W.-J.; Xu, J.-K.; Liu, J.-J.; Lang, J.-J.; Gao, S.-Q.; Wen, G.-B.; Lin, Y.-W. Biotransformation of Lignin by an Artificial Heme Enzyme Designed in Myoglobin With a Covalently Linked Heme Group. Front. Bioeng. Biotechnol. 2021, 9, 664388. [CrossRef]

28. Linde, D.; Pogni, R.; Canellas, M.; Lucas, F.; Guallar, V.; Baratto, M.C.; Sinicropi, A.; Saez-Jimenez, V.; Coscolin, C.; Romero, A.; et al. Catalytic surface radical in dye-decolorizing peroxidase: A computational, spectroscopic and site-directed mutagenesis study. Biochem. J. 2015, 466, 253-262. [CrossRef] [PubMed]

29. Shrestha, R.; Chen, X.J.; Ramyar, K.X.; Hayati, Z.; Carlson, E.A.; Bossmann, S.H.; Song, L.K.; Geisbrecht, B.V.; Li, P. Identification of Surface-Exposed Protein Radicals and A Substrate Oxidation Site in A-Class Dye-Decolorizing Peroxidase from Thermomonospora curvata. Acs Catal. 2016, 6, 8036-8047. [CrossRef]

30. Li, L.L.; Yuan, H.; Liao, F.; He, B.; Gao, S.Q.; Wen, G.B.; Tan, X.; Lin, Y.W. Rational design of artificial dye-decolorizing peroxidases using myoglobin by engineering Tyr/Trp in the heme center. Dalton. Trans. 2017, 46, 11230-11238. [CrossRef] [PubMed]

31. Zhang, P.; Xu, J.; Wang, X.-J.; He, B.; Gao, S.-Q.; Lin, Y.-W. The Third Generation of Artificial Dye-Decolorizing Peroxidase Rationally Designed in Myoglobin. ACS Catal. 2019, 9, 7888-7893. [CrossRef]

32. Liao, F.; Xu, J.K.; Luo, J.; Gao, S.Q.; Wang, X.J.; Lin, Y.W. Bioinspired design of an artificial peroxidase: Introducing key residues of native peroxidases into F43Y myoglobin with a Tyr-heme cross-link. Dalton. Trans. 2020, 49, 5029-5033. [CrossRef] [PubMed]

33. van Bloois, E.; Pazmino, D.E.T.; Winter, R.T.; Fraaije, M.W. A robust and extracellular heme-containing peroxidase from Thermobifida fusca as prototype of a bacterial peroxidase superfamily. Appl. Microbiol. Biot. 2010, 86, 1419-1430. [CrossRef]

34. Uchida, T.; Sasaki, M.; Tanaka, Y.; Ishimorit, K. A Dye-Decolorizing Peroxidase from Vibrio cholerae. Biochemistry 2015, 54, 6610-6621. [CrossRef]

35. Urayama, P.; Phillips, G.N.; Gruner, S.M. Probing Substates in Sperm Whale Myoglobin Using High-Pressure Crystallography. Structure 2002, 10, 51-60. [CrossRef]

36. Maglio, O.; Chino, M.; Vicari, C.; Pavone, V.; Louro, R.O.; Lombardi, A. Histidine orientation in artificial peroxidase regioisomers as determined by paramagnetic NMR shifts. Chem. Commun. 2021, 57, 990-993. [CrossRef]

37. Leone, L.; D’Alonzo, D.; Maglio, O.; Pavone, V.; Nastri, F.; Lombardi, A. Highly Selective Indole Oxidation Catalyzed by a Mn-Containing Artificial Mini-Enzyme. ACS Catal. 2021, 11, 9407-9417. [CrossRef]

38. Liao, F.; He, B.; Du, K.-J.; Gao, S.-Q.; Wen, G.-B.; Lin, Y.-W. Enhanced Dehaloperoxidase Activity of F43Y Myoglobin with a Novel Thyrosine-Heme Crosslink. Chem. Lett. 2016, 45, 1087-1089. [CrossRef]

39. Koduri, R.S.; Tien, M. Oxidation of guaiacol by lignin peroxidase. Role of veratryl alcohol. J. Biol. Chem. 1995, 270, 22254-22258. [CrossRef]

40. Savenkova, M.I.; Kuo, J.M.; Ortiz de Montellano, P.R. Improvement of Peroxygenase Activity by Relocation of a Catalytic Histidine within the Active Site of Horseradish Peroxidase. Biochemistry 1998, 37, 10828-10836. [CrossRef]

41. Fruk, L.; Müller, J.; Niemeyer, C.M. Kinetic analysis of semisynthetic peroxidase enzymes containing a covalent DNA-heme adduct as the cofactor. Chemistry 2006, 12, 7448-7457. [CrossRef] [PubMed]

42. Sinirlioglu, Z.A.; Sinirlioglu, D.; Akbas, F. Preparation and characterization of stable cross-linked enzyme aggregates of novel laccase enzyme from Shewanella putrefaciens and using malachite green decolorization. Bioresour. Technol. 2013, 146, 807-811. [CrossRef] [PubMed] 
43. Rahman Pour, R.; Ehibhatiomhan, A.; Huang, Y.; Ashley, B.; Rashid, G.M.; Mendel-Williams, S.; Bugg, T.D.H. Protein engineering of Pseudomonas fluorescens peroxidase Dyp1B for oxidation of phenolic and polymeric lignin substrates. Enzym. Microb. Technol. 2019, 123, 21-29. [CrossRef] [PubMed]

44. Tonin, F.; Vignali, E.; Pollegioni, L.; D'Arrigo, P.; Rosini, E. A novel, simple screening method for investigating the properties of lignin oxidative activity. Enzym. Microb. Technol. 2017, 96, 143-150. [CrossRef] [PubMed]

45. Caramelo, L.; Martinez, M.J.; Martinez, A.T. A Search for Ligninolytic Peroxidases in the Fungus Pleurotus eryngii Involving $\alpha$-Keto- $\gamma$-Thiomethylbutyric Acid and Lignin Model Dimers. Appl. Environ. Microbiol. 1999, 65, 916-922. [CrossRef]

46. Xu, L.; Sun, J.; Qaria, M.A.; Gao, L.; Zhu, D. Dye Decoloring Peroxidase Structure, Catalytic Properties and Applications: Current Advancement and Futurity. Catalysts 2021, 11, 955. [CrossRef]

47. Sun, L.-J.; Yuan, H.; Xu, J.-K.; Luo, J.; Lang, J.-J.; Wen, G.-B.; Tan, X.; Lin, Y.-W. Phenoxazinone Synthase-like Activity of Rationally Designed Heme Enzymes Based on Myoglobin. Biochemistry 2021, 3, 554. [CrossRef]

48. Ahmad, M.; Roberts, J.N.; Hardiman, E.M.; Singh, R.; Eltis, L.D.; Bugg, T.D. Identification of DypB from Rhodococcus jostii RHA1 as a Lignin Peroxidase. Biochemistry 2011, 50, 5096-5107. [CrossRef]

49. Springer, B.A.; Sligar, S.G. High-level expression of sperm whale myoglobin in Escherichia coli. Proc. Natl. Acad. Sci. USA 1987, 84, 8961. [CrossRef]

50. Bilal, M.; Iqbal, H.M.N.; Hu, H.; Wang, W.; Zhang, X. Enhanced bio-catalytic performance and dye degradation potential of chitosan-encapsulated horseradish peroxidase in a packed bed reactor system. Sci. Total Environ. 2017, 575, 1352-1360. [CrossRef]

51. Vignali, E.; Tonin, F.; Pollegioni, L.; Rosini, E. Characterization and use of a bacterial lignin peroxidase with an improved manganese-oxidative activity. Appl. Microbiol. Biotechnol. 2018, 102, 10579-10588. [CrossRef] 